ment; second segment subclavate, third clavate, fourth elliptico-cylindrical. Mesonotum concealing the pronotum. Superior claws (fig. I8) broad, curving, with a large proximal tooth and a small sharp distal tooth; between these there is, on the hind feet, another minute tooth; inferior claws over half as long as the superiors, oblong-lanceolate; tenent hair small and unknobbed. Fourth abdominal segment nearly four times as long as the third. Furcula attaining the ventral tube; manubrium and dentes subequal; mucrones (fig. 19) subfalcate with two subequal teeth and a prominent basal spine; three barbellate setae surround the mucro and two of them extend far beyond it. Scales large and rounded. A few minute setae occur on the head, stiff bristles on the appendages and curving feathered setae on the dorsal side of the furcula. Length, I $\mathrm{mm}$.

This species bears much resemblance to P. alba Pack. * In alba, however, the proximal tooth of the superior claw is more basal than in candida, while the fourth abdominal segment is only three times as long as the third, and dense clavate setae are present on mesonotum, coxae, and the apex of the abdomen; alba, moreover, has only four eyes.

Three types: 268 (2), 308 (I). Type No. 6r48, U. S. National Museum.

\title{
FURTHER NOTES ON NEW ENGLAND FORMICIDÆ.
}

BY GEO. B. KING, LAWRENCE, MASS.

Last summer Mr. C. Abbott Davis of Providence, Rhode Island, collected with other insects, such species of ants as he found, and later turned them over to me for study. The following is a list of the species taken with localities. The first fifteen are from Rhode Island.

Tapinoma sessile Say.

Providence

Formica fusca $\mathrm{L}$.

Lonsdale

Formica fusca var. subsericea Say.

Providence

Formica rufa subsp. integra Nyl.

Providence \& Kingston

Formica pallidefulva Latr. subsp. schaufussi Mayr.

Providence

Formica lasioides $\mathrm{Em}$.

Providence

Formica gagates Latr.

Providence

Camponotus herculeanus

Latr. subsp.

ligniperdus Latr.

Providence

Camponotus marginatus I atr. var. nearc- ticus Em.

Lasius americanus Em.

Lasius claviger Rog.

Providence

Providence

Providence

Cremastogaster lineolata Say. Lonsdale Myrmica rubra Buck. var. schencki Em.

Providence

Myrmica rubra Buck. subsp. scabrinodis Nyl.

Kingston

Monomorium minutum Mayr. var. minimum Buckl.

Providence.

Three species taken in Vermont. Aphaeogaster fulva Rog. Bay, Vermont Leptothorax canadense Prov. Western Vt. Camponotus maculatus Fabr. subsp. vicinus Mayr. Bay, Vt., and the following at Lynn, Mass.

* See C. Schäffer. Ueber württembergische Collembola, Jahres, ver. vaterl. Naturk. Württemberg, bd. 56 (1900) pp. $245-280$, taf. 6 . See pp. $269-270$. 
Camponotus herculeanus Latr. var. pictus For.

Formica fusca L. subpolita Mayr.

Lasius nigra. $\mathrm{L}$.

The collection consisted of 22 species, of one of which there was not sufficient material for determination, but apparently it is distinct from any species hitherto found in New England.

\section{THE SO-CALLED MANDIBLES OF SPIDERS.}

By William A. Riley, ithacA, N. Y.

Regarding the homologies of the first pair of appendages of the arachnids there has always been a question. According to the prevailing view they correspond to the mandibles of insects and are therefore generally referred to as mandibles. The evidence indicates that this application of the term is incorrect.

In 18 16 Savigny expressed himself against any attempt to homologize the head appendages of the arachnids with those of insects. He believed that in arachnids the first pair of appendages, commonly known as mandibles, in reality represented a modified pair of legs.

A little later Latreille, '29, advanced the view that the so-called mandibles are, in fact, the homologues of the second antennae of Crustacea. He stated that this is evident from a comparison with the second antennae of Crustacea and especially with those of the order Poecilopodes (Limulus.) As indicative of this homology he introduced the term chelicerae, (Gr. chèle, claw + keras, horn), or antennes-pinces.
Following Latreille a number of prominent zoologists have referred to the chelicerae as homologous with the antennae of crustaceans and insects. Thus, Siebold, '48, says "This view of Latreille is the correct one, since the nerves of those organs do not arise from the abdominal ganglia, but directly from the brain, as those of the antennae of Crustacea and Insecta." Ed. Burnett, '54, p. 374. Blackwell, '52, while admitting, as highly probable, this homology, proposes as more non-committal the term falces instead of Latreille's term chelicerae.

While drawing most of their evidence from the Crustacea these authors have uniformly spoken of the appendages in question as corresponding to the antennae of insects. Thus, Simon, '92, p. 29, states that the first antennae of Crustacea are not represented in the arachnids and insects but that the second antennae find their homologues in the antennae of insects and the chelicerae of arachnids.

Those who hold to the view expressed by Simon have fallen into the error of assuming the homology of the antennae of Crustacea and of Hexapoda. But, 

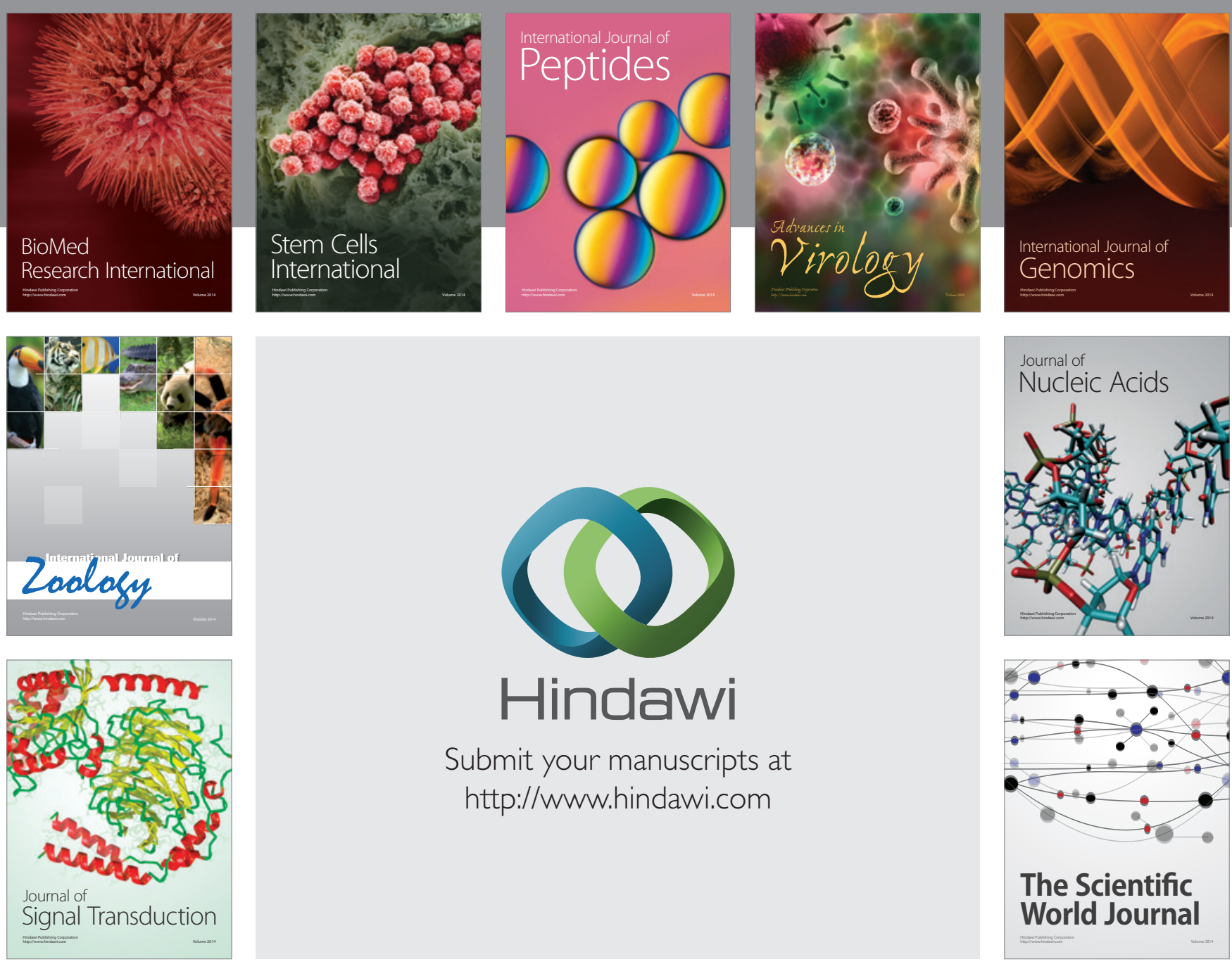

Submit your manuscripts at

http://www.hindawi.com
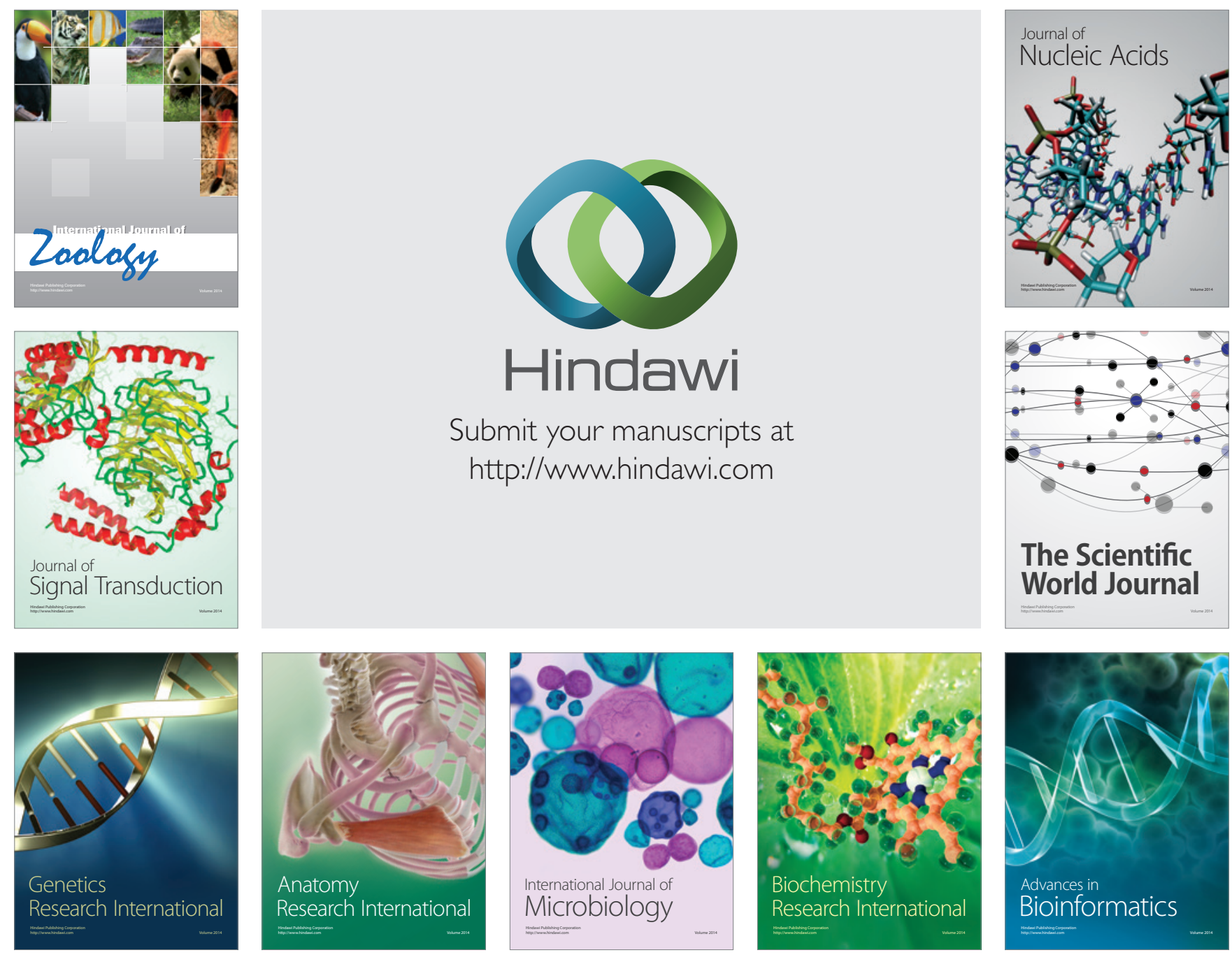

The Scientific World Journal
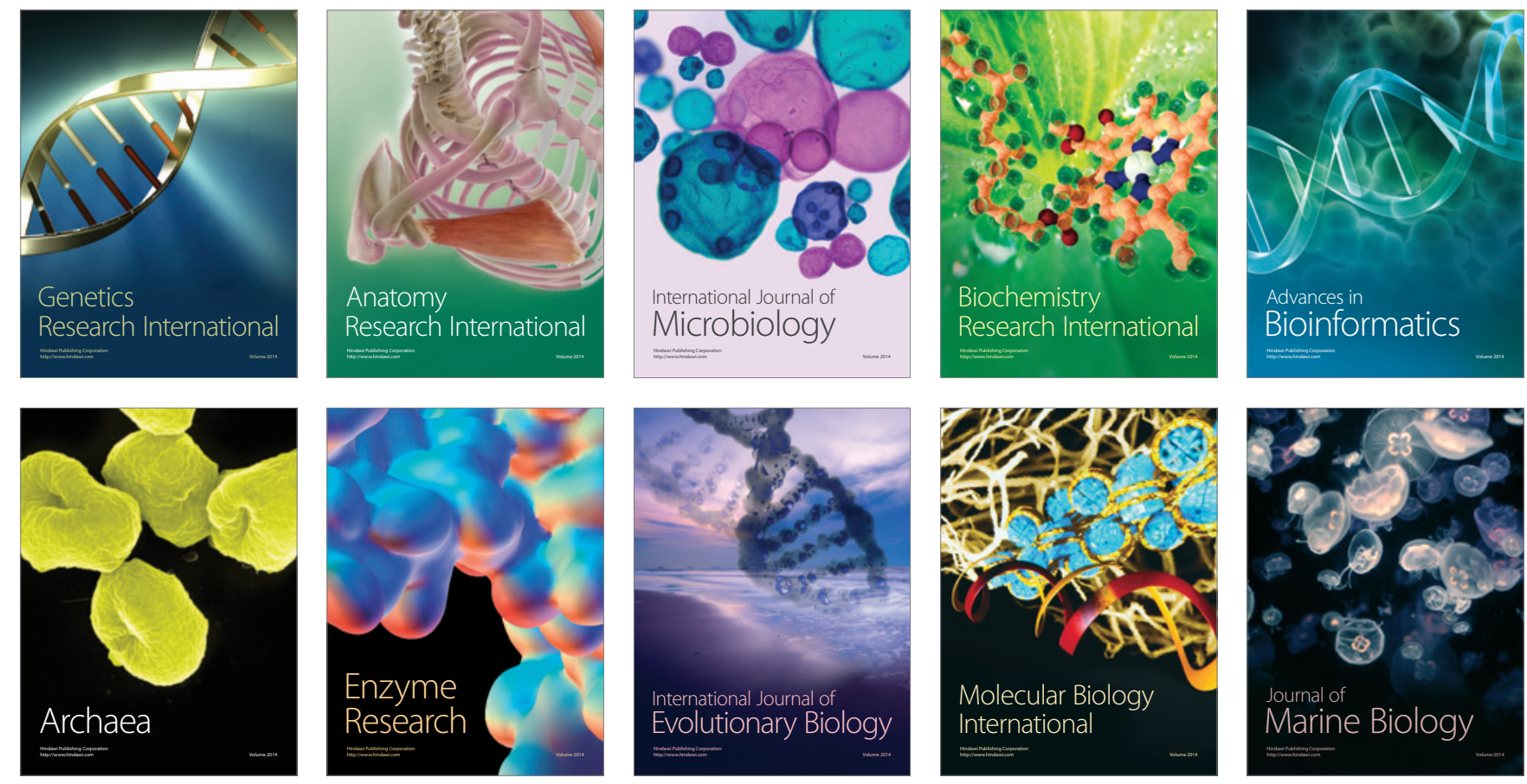